\title{
Low frequency of replication errors in primary nervous system tumours
}

\author{
Maria Jesús Sobrido, Carlos Rodriguez Pereira, Francisco Barros, Jerónimo Forteza, \\ Ángel Carracedo, Manuela Lema
}

\begin{abstract}
Objectives-Automated DNA technology was used to analyze the incidence of microsatellite instability (MIN) among the most frequent types of adult primary CNS tumours and to determine its relation with clinicopathological characteristics.

Methods-Fifty six gliomas, 32 meningiomas and 11 schwannomas were screened for size changes at eight microsatellite loci using fluorescent polymerase chain reaction (PCR) followed by fragment analysis in an automated sequencer. A tumour was considered as MIN+ when a different electrophoretic pattern between constitutional and tumour DNA was evidenced in one or more microsatellite markers and as replication error positive $(\mathrm{RER}+)$ when at least $25 \%$ of the markers analyzed (2/8) showed instability. The MIN phenotype was correlated with relevant clinical and pathological parameters.
\end{abstract}

Results-Globally, instability was found in $19 / 767$ analyses $(2.47 \%)$, with a higher rate among tetranuceotide than dinucleotide repeats $\left(\chi^{2}\right.$ test, $\left.\mathbf{p}=0.018\right)$. Ten gliomas $(17.9 \%)$, two meningiomas $(6.3 \%)$, and two schwannomas $(18.2 \%)$ were MIN+, whereas one glioma $(1.8 \%)$, two meningiomas $(6.3 \%)$, and one schwannoma $(9.1 \%)$ were classified as RER+. A possible association between microsatellite instability and a shorter duration of clinical course was found in meningiomas. The MIN+ phenotype was more frequent in spinal than intracranial schwannomas (Fisher's exact test, $p=0.018$ ). No other significant association with clinical or histological features was detected.

Conclusions-Although microsatellite instability can be demonstrated at a low rate in some primary CNS tumours, a true replication error phenotype (revealed by widespread microsatellite instability at numerous loci) is uncommon and unlikely to play an important part in the pathogenesis of these neoplasms. This form of instability was more frequent in tetranucleotide than in dinucleotide repeats. To our knowledge, this is the first report of MIN in schwannomas, where it was associated with the spinal localisation of the tumour.

(F Neurol Neurosurg Psychiatry 2000;69:369-375)

Keywords: microsatellite instability; central nervous system tumours; automated DNA analysis
Microsatellites are short tandemly repeated DNA sequences (STRs) scattered throughout the genome that are more prone to mutate than other genomic regions. ${ }^{1}$ In recent years a new molecular pathway for carcinogenesis has been characterised which consists of the failure of the cellular mechanisms responsible for maintaining the fidelity of DNA replication. Such a defect would give rise to an increased rate of mutations, some of which could eventually contribute to the neoplastic transformation. ${ }^{2}$ This specific form of genomic instability is evidenced by frequent length alterations in STRs when the tumour is compared with the corresponding constitutional DNA, a phenomenon first described in colorectal carcinomas that has been termed microsatellite instability (MIN) or replication error (RER). ${ }^{3-5}$ The mutator phenotype was later also found in a wide variety of human cancers, both hereditary and sporadic. ${ }^{6-9}$ In some tumours the presence of MIN has been associated with clinical and pathological characteristics. ${ }^{10} 11$ Furthermore, the detection of this phenotype has proved to be of prognostic value in certain types of cancer. Whereas it is associated with a better prognosis in patients with colon and gastric cancer, ${ }^{512}$ it has been related to reduced survival in breast cancer. ${ }^{13}$ Another clinical implication attributed to the MIN phenotype is an increased resistance to some alkylating agents in these tumours. ${ }^{14}$ However, for most MIN+ sporadic cancers its clinical and prognostic significance, as well as its possible association with histopathological features, remain to be established. The first clues to the molecular origin of this phenomenon came with the confirmation of the hypermutability of RER+ cells in vitro, ${ }^{15}$ and its association with mutations in the mismatch repair genes. ${ }^{16}{ }^{17}$ However, many replication error positive tumours failed to show mutations in these genes. ${ }^{18}$ The molecular basis of MIN in these cases is yet unknown.

The role of the replication error phenotype in neoplasms of the nervous system is controversial. Although some investigators have suggested the implication of this type of genetic instability in the development of brain tumours, ${ }^{19-22}$ others failed to find a significant incidence of MIN, even in large series. ${ }^{83-26}$ The MIN+ brain neoplasms seem to be mostly high grade gliomas, ${ }^{19-2123}$ although some researchers have also reported microsatellite instability in meningiomas. ${ }^{22}{ }^{23}$ Microsatellite instability has also been detected in neurofibromas of patients with neurofibromatosis type $1,{ }^{27}$ but has not been reported in other nerve sheath tumours. 
Table 1 Characteristics of the STRs analyzed

\begin{tabular}{|c|c|c|c|c|c|}
\hline Marker & Type & Location & Primers & Annealing & Reference \\
\hline FIBRA/FGA & Tetra & $4 \mathrm{q}$ & $\begin{array}{l}\text { ^5'-GCCCCATAGGTTTTGAACTCA-3' } \\
\text { 5'-TGATTTGTCTGTAATTGCCAGC-3' }\end{array}$ & $60^{\circ} \mathrm{C}$ & 36 \\
\hline D21S11 & Tetra & $21 \mathrm{q}$ & $\begin{array}{l}\text { ^5'-ATATGTGAGTCAATTCCCCAAG-3' } \\
\text { 5'-TGGAGAACATTAACTAATACA-3' }\end{array}$ & $60^{\circ} \mathrm{C}$ & 37 \\
\hline D12S391 & Tetra & 12 & $\begin{array}{l}\text { ^5'-TGGCTTTTAGACCTGGACTG-3' } \\
\text { 5'-AACAGGATCAATGGATGCAT-3' }\end{array}$ & $61^{\circ} \mathrm{C}$ & 38 \\
\hline D19S394 & Tetra & $19 p$ & $\begin{array}{l}\text { ^5'-GTGTTCCTAACTACCAGGC-3' } \\
\text { 5'-AGACTACAGTGAGCTGTGG-3' }\end{array}$ & $56^{\circ} \mathrm{C}$ & 39 \\
\hline D1S1656 & Tetra & 1 & $\begin{array}{l}\text { ^5'-GTGTTGCTCAAGGGTCAACT-3' } \\
\text { 5'-AGAAATAGAATCACTAGGGAACC-3' }\end{array}$ & $59^{\circ} \mathrm{C}$ & 40 \\
\hline D6S1583 & $\mathrm{Di}$ & $6 \mathrm{p}$ & $\begin{array}{l}\text { ^5'-GCCCCTAACCTGCTTCTACTGA-3' } \\
\text { 5'-GCAGATGGCCCCACTGAC-3' }\end{array}$ & $63^{\circ} \mathrm{C}$ & 39 \\
\hline D9S153 & Di & $9 \mathrm{q}$ & $\begin{array}{l}\text { ^5'-TTATGGCAGCCCAAATGGACTA-3' } \\
\text { 5'-GCAGAATGTTGCCCAAAACTCA-3' }\end{array}$ & $67^{\circ} \mathrm{C}$ & 39 \\
\hline D9S1867 & $\mathrm{Di}$ & $9 \mathrm{q}$ & $\begin{array}{l}\text { ^5'-GTGAACTGCATCAGCCG-3' } \\
\text { 5'-ATCAGCCAGGGTTTTCAACA-3' }\end{array}$ & $61^{\circ} \mathrm{C}$ & 39 \\
\hline
\end{tabular}

One primer of each pair-indicated with an asterisk-was fluorescently labelled.

$\mathrm{Di}=$ dinucleotide repeat; Tetra $=$ tetranucleotide repeat.

The heterogeneity of the previous data can in great measure be attributed to the lack of a generally accepted definition of the RER status (type and number of STRs that have to be analyzed and number of unstable loci that have to be detected) as well as to the different sensitivity and specificity of the methods used for the analysis. In recent years, the introduction of fluorescence based automated DNA sequencers has greatly improved the analysis of genetic markers. ${ }^{28}$ Compared with conventional techniques, this method provides more accurate sizing of alleles and increases the sensitivity, reproducibility, and throughput of reliable data for the evaluation of MIN. ${ }^{29} 30$ The aim of our study was to use fluorescence based polymerase chain reaction (PCR) and automated DNA analysis to investigate the role of the mutator phenotype in the development of the most common tumour types of the CNS. Although this approach has already been used for the detection of MIN in several human non-CNS cancers, the present study is only the second using fluorescence based technology in gliomas and the first in meningiomas and schwannomas. We also analyze the relation of the MIN status to relevant clinicopathological parameters.

\section{Materials and methods}

PATIENTS AND TUMOUR SAMPLES

Initially, all samples from surgical resection or stereotactic biopsy of gliomas, meningiomas, or schwannomas in the Complejo Hospitalario Universitario de Santiago (CHUS) during the period 1987-97 were candidates to be included in the study. Additional inclusion criteria were: (a) the patient's informed consent; (b) sufficient amount of sample ( $>0.5 \mathrm{~cm}^{2}$ of tissue); (c) absence of diagnostic or gradation uncertainty; (d) availability of clinical data. Formalin fixed, paraffin embedded tumour specimens of 113 patients that fulfilled these criteria were obtained from the pathology archives of the CHUS, a $4 \mu \mathrm{m}$ section was stained using routine procedures, and the diagnosis was reviewed by an experienced pathologist according to the last World Health Organisation (WHO) classification. ${ }^{31}$ The grading of gliomas was based on the St Anne Mayo scheme. ${ }^{32}$
DNA ISOLATION

If more than $80 \%$ of the tissue corresponded to malignant cells, a $10 \mu \mathrm{m}$ unstained section was deposited in a centrifuge tube and used for DNA extraction. When a significant proportion of histologically normal tissue was present, an additional $10 \mu \mathrm{m}$ section was stained with toluidine blue and used to microdissect appropiate areas of tumour. We avoided haematoxylin and eosin stained samples as a source of DNA because this dye has been shown to affect PCR efficiency. ${ }^{33}$ Isolation of DNA from paraffin embedded tissue was based on the previously described method, with slight modifications. ${ }^{34}$ Briefly, tissue sections were deparaffinised and incubated at $56^{\circ} \mathrm{C}$ for 2 hours in 50-100 $\mu 1$ digestion buffer. ${ }^{35}$ Alternatively, some samples were incubated at $37^{\circ} \mathrm{C}$ overnight. Finally, proteinase $\mathrm{K}$ was inactivated at $95^{\circ} \mathrm{C}$ for 10 minutes. Peripheral blood leucocytes were used as a source of constitutional DNA, which was isolated by standard proteinase $\mathrm{K}$ digestion and phenol-chloroform extraction.

\section{FLUORESCENT PCR}

Three dinucleotide (D6S1583, D9S153, D9S1867) and five tetranucleotide repeat markers (humFibra/FGA, D21S11, D12S391, D19S394, D1S1656 ) were amplified by PCR under optimised conditions. Primers were commercially purchased (Amersham Pharmacia Biotech, APB) according to the published sequences (table 1). One primer of each pair was fluorescently labelled with Cy5. Conditions for PCR were as follows: $50 \mathrm{ng}$ template DNA, $10 \mathrm{mM}$ Tris- $\mathrm{HCl}, 50 \mathrm{mM} \mathrm{KCl}, 1.5 \mathrm{mM}$ $\mathrm{MgCl}_{2}, 200 \mu \mathrm{M}$ of each dNTP, 10 pmol of each primer and 1.25 units Taq polymerase ${ }^{\mathbb{B}}$ (Gibco) in a final volume of $25 \mu$ l. Reactions were performed in a Progene ${ }^{\mathbb{B}}$ thermal cycler (Techne) and consisted of an initial denaturation step at $95^{\circ} \mathrm{C}$ for 5 minutes followed by 30 cycles of 30 seconds at $94^{\circ} \mathrm{C}, 30$ seconds at the appropriate annealing temperature, and 45 seconds at $72^{\circ} \mathrm{C}$.

ANALYSIS OF PCR PRODUCTS AND ASSESSMENT OF MICROSATELLITE INSTABILITY

One microlitre of the PCR product was mixed with $1 \mu \mathrm{l}$ of each size marker and $4 \mu \mathrm{l}$ 
formamide solution, denatured, and electrophoresed in a denaturing polyacrylamide gel (5.7\% acrylamide, $0.3 \%$ bisacrylamide, $7 \mathrm{M}$ urea) using an ALFExpress ${ }^{\circledR}$ sequencer (APB). The running conditions were $1500 \mathrm{~V}$ and $25 \mathrm{~W}$ at a constant temperature of $55^{\circ} \mathrm{C}$ for 130 minutes with a running buffer of $0.6 \mathrm{X}$ TBE. The data were processed using the Allelelinks ${ }^{\circledR}$ software version 1.00 (APB). The alleles were automatically sized by the inclusion in each lane of two fluorescent PCR products of known size and the electrophoretic patterns obtained from normal and tumour DNA of each patient were compared. MIN was defined by the presence of novel alleles in tumour DNA that were not present in the corresponding constitutional DNA, providing that: (1) the novel peak(s) did not correspond to stutter bands or non-specific artifacts characteristic of that STR; (2) the same pattern was obtained in at least two independent analyses; and (3) the sample was not clearly degraded, as disclosed by the inability to amplify all or most of the STRs. Although there is a lack of general agreement for the assessment of microsatellite instability, it has been suggested that at least $20 \%$ of the loci should be unstable to consider that a neoplasm exhibits the replication error phenotype, whereas tumours with less than $10 \%$ instability have not been associated with damage in the mechanisms of DNA repair. ${ }^{41}$ Therefore, for the purposes of this study, tumours with instability in at least two STRs were classified as RER+, and those with only one unstable STR were classified as MIN+ but not RER+.

\section{CLINICOPATHOLOGICAL DATA AND STATISTICAL} ANALYSIS

Out of the 113 selected samples, 12 gliomas, one meningioma, and one schwannoma repeatedly failed to give any amplification products and were thus also excluded from the study. This left a final series of 99 evaluable tumours with the following distribution: 56 gliomas (G1-G56), 32 meningiomas (M1-M32), and 11 schwannomas (N1-N11). The clinicopathological features of these cases were retrospectively collected from clinical records.

\section{Gliomas ( $n=56)$}

The distribution of the gliomas by histological type and grade was: 40 astrocytomas (15 low grade, eight anaplastic, 17 glioblastomas), seven oligodendrogliomas (six low grade, one anaplastic), six mixed oligoastrocytomas (five low grade, one anaplastic), one pilocytic astrocytoma, one pleomorphic xantoastrocytoma, and one anaplastic ganglioglioma. The pilocytic astrocytoma, the pleomorphic xantoastrocytoma, and the anaplastic ganglioglioma were included to calculate the global rate of microsatellite instability in glial tumours, but were not taken into account for other statistical purposes. Also, for statistical reasons in the present study oligodendrogliomas and mixed oligoastrocytomas were considered as a group, distribution supported by previous evidence of molecular and prognostic similarities of both types of gliomas compared with astrocytomas. ${ }^{42}$ Nineteen $(33.9 \%)$ of the pa- tients with gliomas were female and 37 $(66.1 \%)$ male, with a mean age of 50.5 years (range 16-77). The mean duration of symptoms at the time of diagnosis was 14.2 months (range 0.25-168). The mean tumour size measured on neuroimaging was $4.5 \mathrm{~cm}$ (range $1-10 \mathrm{~cm})$. Most tumours (53/56; 94.6\%) were supratentorial. Given the wide distribution of tumour site and the few cases in a given location, it was not possible to classify them into reasonable categories and this parameter had to be excluded from statistical analysis.

\section{Meningiomas $(n=32)$}

Twenty eight $(87.5 \%)$ were grade I, three $(9.4 \%)$ grade II, and one $(3.1 \%)$ grade III according to the WHO classification. ${ }^{31}$ Seven $(21.9 \%)$ of the patients with meningiomas were male and $25(78.1 \%)$ were female. The mean age was 57.6 years (range 38-79). One of the tumours was an incidental finding. The mean clinical course for the rest of the cases was 22.2 months (range $0.5-120$ ). For statistical purposes they were divided into the following location categories: (1) cerebral hemispheres (convexity and parasagittal) 17 (53.1\%), and (2) media or posterior fossae 15 $(46.9 \%)$. The mean tumour size was $4.25 \mathrm{~cm}$ (range 1-6.8). Four meningiomas had macroscopic bone reaction recognisable on the neuroimage (two osteoblastic, two osteolitic). The intensity of surrounding oedema was evaluated on CT and classified into: (1) absent (0) or mild (+) and (2) moderate $(++)$ or intense $(+++)$. Four patients $(12.5 \%)$ had multiple meningiomas. Only one of the tumours was studied in each case.

Schwannomas $(n=11)$

Nine $(81.8 \%)$ were acoustic neuromas and two $(18.2 \%)$ spinal schwannomas. The mean tumour size was $3.54 \mathrm{~cm}$ (range 1.8-8). Three $(27.3 \%)$ were from male and eight $(72.7 \%)$ from female patients of a mean age of 54.4 years (range 42-72). Two of the tumours were incidental findings, the rest with a mean duration of symptoms at diagnosis of 24.2 months (range 0.5-156).

The association of MIN status with the clinicopathological parameters was evaluated by means of $\chi^{2}$ test, Fisher's exact test and MannWhitney $U$ test where appropriate, using the statistical package SPSS $^{\circledR} 6.0$ for Windows. The significance threshold was set at $\mathrm{p}<0.05$.

\section{Results}

Ninety nine sporadic neoplasms of the nervous system and corresponding leucocyte DNA were evaluated at eight microsatellite loci using fluorescent PCR and an automated DNA sequencer. The other 14 tumour samples initially selected for the screening yielded no results due to PCR failure.

Fourteen tumours $(14.1 \%)$ exhibited MIN in at least one marker. The RER+ phenotype (MIN in at least two loci) was found in four cases (4\%). It was possible to interpret unambiguously $767 / 792(96.8 \%)$ of the analyses, with $19 / 767$ unstable loci, which gives a global rate of instability of $2.47 \%$ for these tumours. 

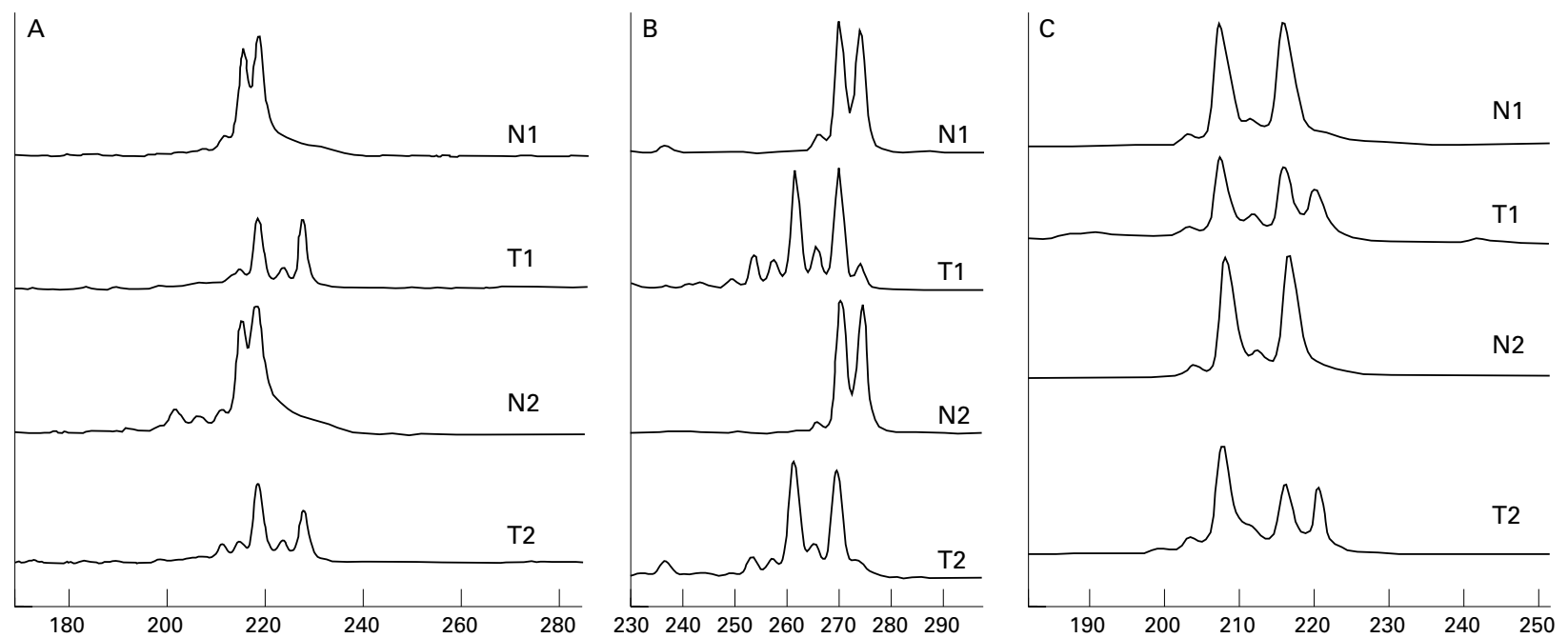

Examples of electropherograms exhibiting MIN. (A) D12S391, case G46; (B) D19S394, case M29; (C) D12S391, case G10. The bottom line indicates size in base pairs. N=normal DNA sample; T=tumour DNA. The subindices 1 and 2 refer to the first and second independent PCRs, respectively.

Two out of 292 evaluable dinucleotide $(0.7 \%)$ and 17 out of 475 (2.9\%) tetranucleotide repeats showed extra peaks on the electrophoretogram which were not present in the normal paired DNA. Thus, tetranucleotide STRs exhibit a higher rate of instability than dinucleotides in these neoplasms $\left(\chi^{2}\right.$, $p=0.018)$. Some of the patterns of instability detected are shown in the figure.

We have analyzed the frequency of microsatellite instability with respect to relevant clinicopathological variables. Ten out of $56(17.9 \%)$ tumours of glial origin showed instability in at least one locus. The distribution by histological type was $8 / 40(20 \%)$ astrocytic tumours, $1 / 13$ $(7.7 \%)$ oligodendroglial and mixed tumours, $1 / 1(100 \%)$ ganglioglioma, $0 / 1(0 \%)$ pilocytic astrocytoma, and 0/1 (0\%) pleomorphic xantoastrocytoma. The incidence of MIN among low and high grade gliomas was compared after stratification by histological type. The different frequency of instability among high and low grade astrocytomas $(28 \%$ and $6.7 \%$, respectively) was not statistically significant. Only one of the gliomas $(1.8 \%)$ showed MIN at two loci and was classified as RER+. Interestingly, this tumour is a low grade astrocytoma from a patient without a family history of neoplasia. There was no significant association between the presence of MIN in gliomas and the patient's age, sex, tumour size, or duration of clinical course to diagnosis.

Two out of 32 meningiomas (6.3\%) showed instability, one of them at two and another at three loci. Both are grade II meningoteliomatous meningiomas without histological signs of atypia or malignancy. One of them exhibited a striking osteolytic component recognisable on the neuroimage. The mean duration of clinical course to diagnosis for the MIN+ meningiomas was 0.75 (0.0) months, compared with 23.63 (29.7) months for the MIN- tumours (Mann-Whitney $U$ test, $\mathrm{p}=0.017$ ). The rest of the evaluated parameters did not differentiate meningiomas with from those without instability.
There were two $(18.2 \%) \mathrm{MIN}+$ schwannomas, one of them $(9.1 \%)$ at two STRs. These tumours were the two extracranial schwannomas included in our series, one located at C2 and the other at L3. Thus, a statistically significant association was seen between the presence of MIN in spinal versus cranial schwannomas (Fisher's exact test, $\mathrm{p}=0.018$ ), while no differences were detected for sex, age, duration of symptoms and tumour size between MIN+ and MIN- schwannomas.

\section{Discussion}

A mutator phenotype, characterised by abundant DNA repair errors, has been implicated in the development of human cancer. An increased rate of replication errors might eventually lead to genetic alterations involved in the multistage neoplastic transformation. ${ }^{43} \mathrm{Re}-$ cently, a support for this hypothesis came from the identification in various malignancies of widespread instability at repetitive DNA sequences (microsatellites), which can be recognised as the presence of new alleles in the tumour when compared with the constitutional DNA and has been associated with mutations in the mismatch repair genes. ${ }^{3-5} 16$

We screened 113 CNS tumours of different types at eight STR loci using a fluorescence based automated DNA analysis. A total of 767 sequences were evaluated. Although DNA obtained from paraffin embedded archival brain tissue was generally suitable for PCR, 14 samples repeatedly failed to amplify and were excluded from all final statistical considerations. Due to the retrospective nature of the study, we did not have a strict control on the way that these samples had been handled. Some of them were more than 10 years old and, although all had been routinely preserved, variability in the fixation time may also account for a higher degradation of the nucleic acid. ${ }^{44}$ Instability of at least one STR was found in $13 / 99(13.1 \%)$ tumours and 19/767 $(2.47 \%)$ of the analyses. Only four samples $(4 \%)$ showed MIN at high frequency (at least $25 \%$ of the loci). Thus, based on our results the replication 
Table 2 Microsatellite instability in gliomas

\begin{tabular}{|c|c|c|c|c|c|c|c|}
\hline Study & $n$ & Type and grade (n) & $\begin{array}{l}\text { STRs } \\
\text { examined }\end{array}$ & Method & $\begin{array}{l}\text { MIN+ } \\
\text { tumours } \\
(\%)\end{array}$ & $\begin{array}{l}\text { Evaluable } \\
\text { analyses } \\
(n)^{\star}\end{array}$ & $\begin{array}{l}\text { Positive } \\
\text { analyses } \\
(\%)^{\star}\end{array}$ \\
\hline Wooster et al $1994^{8}$ & 32 & NS & 12 & Radioactive & 3.1 & 384 & 0.26 \\
\hline Dams et al $1995^{19}$ & 16 & $\mathrm{AI}(1) \mathrm{A}(4) \mathrm{AA}(1) \mathrm{GM}(10)$ & 17 & Radioactive & 31 & 264 & 1.9 \\
\hline Zhu et al $1996^{23}$ & 62 & $\begin{array}{l}\mathrm{As}(33) \ddagger \mathrm{ODG}(15) \\
\mathrm{AODG}(8) \mathrm{GG}(6)\end{array}$ & 5 & Radioactive & 8.1 & 720 & 1.25 \\
\hline Izumoto et al $1997^{20}$ & 40 & $\mathrm{~A}(5) \mathrm{AA}(11) \mathrm{GM}(24)$ & 2 & Radioactive & 18 & 80 & 11.25 \\
\hline Zhu et al $1998^{24}$ & 25 & ODG(16) AODG(9) & 132 & Radioactive & 76 & 3135 & 1.4 \\
\hline Lundin et al $1998^{25}$ & 26 & $\begin{array}{l}\text { GM(15)AA(4) AODG(1) } \\
\mathrm{OA}(2) \mathrm{AOA}(4)\end{array}$ & $3 \dagger$ & Radioactive & $<3.9$ & 174 & $<0.45$ \\
\hline Mizoguchi et al $1999^{21}$ & 31 & $\begin{array}{l}\text { GM(11) AA(8) AODG(2) } \\
\text { A(5) GA(1) OA(1) } \\
\text { ODG(1) PA(3) }\end{array}$ & 5 & Fluorescent & 22.6 & 146 & 9.6 \\
\hline The present study & 56 & $\begin{array}{l}\mathrm{GM}(17) \mathrm{AA}(8) \mathrm{A}(15) \mathrm{ODG}(6) \\
\text { AODG(1)OA(5)OA(1)PA(1) } \\
\text { PXA(1) AGG(1) }\end{array}$ & & Fluorescent & 17.9 & 435 & 2.52 \\
\hline
\end{tabular}

$\mathrm{n}=$ Number of cases; NS=not specified; $\mathrm{AI}=$ grade I astrocytoma; $\mathrm{A}=$ fibrillary astrocytoma (grade $\mathrm{II}) ; \mathrm{AA}=$ anaplastic astrocytoma

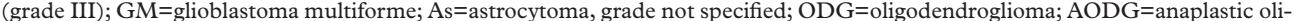
godendroglioma; $\mathrm{OA}=$ mixed oligoastrocytoma; $\mathrm{AOA}=$ anaplastic oligoastrocytoma; $\mathrm{GG}=$ ganglioglioma; $\mathrm{AGG}=$ anaplastic ganglioglioma. PA=pilocytic astrocytoma; PXA=pleomorphic xantoastrocytoma; GA=gemistocytic astrocytoma.

$¥ 13 \mathrm{GM}$, for the other 20 grade was not indicated.

^For those works where these figures were not specifically given, they were calculated considering that all the markers were unambiguously interpreted for all the tumours analyzed.

$\dagger 16$ of the samples were analyzed at nine additional loci.

error is not likely a causal mechanism in these tumours. In tables $2-4$ we summarise the results of microsatellite analysis in the present and other works, although the comparison is hampered by the different number and type of STRs screened, as well as the scarce clinical and histological data provided in some of the studies.

GLIOMAS

In the present series, ten gliomas $(17.9 \%)$ exhibited instability in a total of 11 loci $(2.52 \%)$. Only one of them $(1.8 \%)$ showed MIN in two STRs and was classified as RER+. Out of $54 \mathrm{CNS}$ neoplasms of different types, Wooster et al found MIN in only one glioblastoma, which represented the lowest rate of instability among all the tumours in their study. ${ }^{8}$ Lundin et al found no length alterations at all in their series of gliomas. ${ }^{24}$ Our data and those from others, however, indicate that MIN can be detected in some proportion of gliomas, the frequency of instability still being very low when compared with mismatch repair deficient tumours. ${ }^{19-21}$ Except for the finding of MIN positive oligodendrogliomas by Zhu et al, ${ }^{24}$ all previously reported MIN+ gliomas are high grade tumours. $^{819-21}$ This has led to the suggestion that microsatellite instability might be related to malignant progression and poor prognosis. ${ }^{1921}$ Our results do not support this hypothesis. In the present study MIN was more frequent among high grade gliomas, but the difference was not statistically significant. Furthermore, the only MIN+ oligodendroglioma was a low grade tumour and the only RER+ among our series of gliomas was a low grade astrocytoma. Therefore, we find the evaluation of MIN of no prognostic value in these tumours. By histological type, the rate of MIN was lower in the oligodendroglioma/ oligoastrocytoma group $(7.7 \%)$ than among the astrocytomas $(20 \%)$, but the difference was not significant. In their first study of 144 primary brain tumours, Zhu et al detected more frequency of instability among oligodendrogliomas. Compared with $3 \%$ of astrocytomas, $17.4 \%$ of oligodendrogliomas $(50 \%$ of anaplastic oligodendrogliomas) exhibited instability. ${ }^{23}$ But when the screening was

Table 3 Microsatellite instability in meningiomas

\begin{tabular}{|c|c|c|c|c|c|c|c|}
\hline Study & $n$ & Grade (n) & $\begin{array}{l}\text { STRs } \\
\text { examined }\end{array}$ & Method & $\begin{array}{l}\text { MIN+ } \\
\text { tumours (\%) }\end{array}$ & $\begin{array}{l}\text { Evaluable } \\
\text { analyses } \\
(n)^{\star}\end{array}$ & $\begin{array}{l}\text { Positive } \\
\text { analyses }(\%)^{*}\end{array}$ \\
\hline Wooster et al $1994^{8}$ & NS & NS & 12 & Radioactive & 0 & NE & 0 \\
\hline Pykett et al $1994^{22}$ & $16 \dagger$ & NS & 4 & Radioactive & 25 & 74 & 27 \\
\hline Simon et al $1996^{26}$ & 44 & I(18) II(15) III (11) & 33 & Silver staining & 0 & 1452 & 0 \\
\hline Zhu et al $1996^{23}$ & 10 & NS & 5 & Radioactive & 0 & 50 & 0 \\
\hline Kirsch et al $1997^{45}$ & 60 & NS & 8 & Radioactive & 1.8 & 480 & 0.41 \\
\hline The present study & 32 & I(28) II(3) III (1) & 8 & Fluorescent & 6.3 & 244 & 2.04 \\
\hline
\end{tabular}

$\mathrm{N}=$ number of cases; $\mathrm{NS}=$ not specified.

^For those works where these figures were not specifically given, they were calculated considering that all the markers were unambiguously interpreted for all the tumours analyzed.

†14 sporadic meningiomas and two meningioma cell lines.

Table 4 Microsatellite instability in schwannomas

\begin{tabular}{llllllll}
\hline Study & $n$ & $\begin{array}{l}\text { Type of tumour } \\
(n)\end{array}$ & $\begin{array}{l}\text { STRs } \\
\text { examined }\end{array}$ & Method & $\begin{array}{l}\text { MIN+ } \\
\text { tumours (\%) }\end{array}$ & $\begin{array}{l}\text { Evaluable } \\
\text { analyses (n) }\end{array}$ & $\begin{array}{l}\text { Positive } \\
\text { analyses (\%) }\end{array}$ \\
\hline $\begin{array}{lllll}\text { Wooster } \text { et al } 1994^{8} \\
\text { Zhu } \text { et al } 1996^{23}\end{array}$ & NS & NS & 12 & Radioactive & 0 & NS & 0 \\
The present study & 10 & Vestibular (10) & 5 & Radioactive & 0 & 50 & 0 \\
& 11 & $\begin{array}{l}\text { Vestibular (9) } \\
\text { Spinal (2) }\end{array}$ & 8 & Fluorescent & 18.2 & 88 & 3.4 \\
\hline
\end{tabular}

$\mathrm{N}=$ number of cases; $\mathrm{NS}=$ not specified. 
extended to 25 oligodendrogliomas using 132 STRs, only $1.7 \%$ of the loci in oligodendrogliomas and $1.0 \%$ in anaplastic oligodendrogliomas showed instability. ${ }^{24}$ Although all the MIN+ glial tumours in other studies are astrocytomas, in many instances no or a limited number of oligodendroglial neoplasms were analyzed. ${ }^{19}{ }^{21} 22$ Thus, by contrast with other cancers,${ }^{10}{ }^{11}$ there is so far no evidence that the MIN phenotype can differentiate histological subsets of gliomas. There was no association between MIN and age, sex, or tumour size. Although we did not find significant differences on comparing the MIN+ and MIN- gliomas for the duration of clinical course, a lack of association here cannot be firmly concluded, given the large SDs.

\section{MENINGIOMAS}

Two meningiomas $(6.3 \%)$ showed instability at a total of five loci $(2.04 \%)$. Although both were grade II tumours, the present series does not allow us to draw conclusions about the association of MIN with tumour grade. One of the MIN+ tumours (M22), located at the hemispheric convexity, exhibited macroscopic osteolitic activity and intense oedema (data not shown). M29 is a meningioma of the cerebellar convexity. No differences were detected between MIN+ and MIN- meningiomas for sex, age, tumour grade, localisation, size, intensity of peritumourus oedema, and presence of bone reaction or multiple tumours. The only feature that differentiates these two meningiomas is a shorter time of clinical course before the diagnosis compared with the MIN- group (MannWhitney $U$ test, $\mathrm{p}=0.017$ ), a feature which might be interpreted as an indicator of a more aggressive clinical behaviour, but could also be an aleatory result due to the few cases. When comparing the incidence of MIN in meningiomas reported in the literature, again, the estimates vary widely. Whereas Pykett et al found MIN in $25 \%$ of the tumours examined and suggested a previously unrecognised role of this phenomenon in meningioma formation, ${ }^{22}$ other researchers did not report any case of instability among meningiomas. ${ }^{86}$ Our results are consistent with the findings of Zhu et al and Kirsh et al, who reported $2.4 \%$ and $1.8 \%$ of $\mathrm{MIN}+$ meningeal tumours, respectively. ${ }^{23} 45$ Together, we interpret these figures as evidence that microsatellite instability is uncommon in meningiomas. It is interesting however that, except for the only meningioma with one unstable locus in the study by Zhu et al, all the other MIN+ meningiomas described in the literature, including the two tumours in the present series, are unstable at two or more loci. In gliomas, on the contrary, only $1 / 10 \mathrm{MIN}+$ tumours in the present study was unstable at more than one locus; this might indicate a different molecular basis for MIN in both types of tumours.

SCHWANNOMAS

We detected two (18.2\%) MIN+ schwannomas, one of them $(9.1 \%)$ at two loci. The global rate of instability in these tumours was $3.4 \%$. Ottini et al described $50 \%$ of neurofibro- mas in patients with neurofibromatosis type 1 with MIN, ${ }^{27}$ but there are no previous reports on MIN+ schwannomas. Wooster et al, who evaluated an unspecified number of schwannomas, did not find any case of instability. ${ }^{8} \mathrm{Zhu}$ et al found no MIN in 10 vestibular schwannomas studied by them. ${ }^{20}$ Both MIN+ schwannomas in our study are spinal tumours. N3 was the second resection of a C2 tumour that had not been irradiated or received any oncological treatment before. N8 was at L3 and had otherwise no remarkable features. Thus, spinal schwannomas could represent a histological subset with a different molecular pathogenesis, although this association will need to be confirmed with more extensive series. Interestingly, there are also reports of association between RER and the localisation of the tumour in colon and gastric cancers. ${ }^{511}$

\section{Summary}

The comparison of data from independent studies is not straightforward and may indeed be difficult, due to: (a) different number and type of STRs analysed; (b) unhomogeneous criteria used to classify a locus as unstable and a tumour as MIN+ or RER+; (c) the global rate of instability (percentage of unstable loci out of total number of loci analysed) is not always provided; (d) different analysis techniques. The introduction of automated DNA sequencers is greatly helping to overcome some of these difficulties and to standardise the evaluation of microsatellites for many purposes. The advantages of fluorescence based DNA analysis over conventional methods for the investigation of MIN have been previously emphasised. ${ }^{29} 30$ Compared with manual electrophoresis, the automated apparatus provides high throughput and increased accuracy and reproducibility in the allele size estimation of amplified STRs. The generalisation of this technique will facilitate the establishment of common objective criteria, facilitate the comparison of data, and will thus allow a more precise judgment of the role of MIN in the carcinogenesis of nervous system tumours.

Although the analysis of microsatellites has proved a useful tool for the study of hereditary non-polyposis colorectal cancer (HNPCC), the evidence for the role of the replication error phenotype in sporadic cancers is conflicting. Globally, we found RER+ phenotypes in a minor subset of tumours. The percentage of tumours with instability in at least one STR was $<20 \%$ and the global rate of instability $<4 \%$. These figures are similar to those described in other sporadic tumours, with a low rate of instability. ${ }^{46}$ On the contrary, HNPCC and other neoplasms with alterations of the mismatch repair system characteristically show a more widespread pattern of microsatellite alterations, the number of MIN+ tumours being usually above $70 \%$ and the ratio of unstable loci to all investigated loci being greater than $10 \%{ }^{3}$ Furthermore, the type of microsatellites with instability in both groups of tumours seems to be different. Although mononucleotide and dinucleotide repeats are the most commonly affected STRs in 
HNPCC, longer STRs seem to be the most often altered in cancers with a low rate of instability. ${ }^{8}$ Tetranucleotide repeats were significantly more affected than dinucleotide repeats in our series. Also the loci examined in the first study of Zhu et $a l^{3}$ were mostly trinucleotide or tetranucleotide repeats, whereas in their second study ${ }^{24}$ they included 128 dinucleotide and only four tetranucleotide repeats, which could account for the different rate of MIN found by these authors in both investigations. According to this, two mechanisms have been proposed for microsatellite instability: one, the inactivation of mismatch repair genes (responsible for the mutator phenotype seen in HNPCC, with instability in smaller repeats), and a second, still unclear mechanism, that would give rise to instability of trinucleotide and tetranucleotide repeats. Thus, we conclude that a true mutator phenotype is not implicated in the development of most primary nervous system cancers and that mismatch repair genes are unlikely to play a key part in their pathogenesis. However, our results also point to the possible involvement of this type of genetic instability in some small subgroups of gliomas, meningiomas, and schwannomas, which deserves further assessment with larger series and under the light of more uniform criteria and methods of analysis.

This work was supported by the grant DGCICYT SAF96-1597 from the Spanish Interministerial Commission of Science and Technology and by the Institute of Neurological Sciences Pedro Barrié de la Maza. We thank Dr Daniel H Geschwind, for his critical review of the manuscript. We are also indebted to Bonita Porch for her editorial assistance.

1 Weber JL, Wong C. Mutation of human short tandem repeats. Hum Mol Genet 1993;2:1123-8.

2 Loeb LA. Microsatellite instability: marker of a mutator phenotype in cancer. Cancer Res 1994;54:5059-63.

3 Aaltonen LA, Peltomaki P, Leach FS, et al. Clues to the pathogenesis of familial colorectal cancer. Science 1993; 260:812-16.

4 Ionov Y, Peinado MA, Malkhosyan S, et al. Ubiquitous somatic mutations in simple repeated sequences reveal a new mechanism for colonic carcinogenesis. Nature 1993; 363:558-61.

5 Thibodeau SN, Bren G, Shaid D. Microsatellite instability in cancer of the proximal colon. Science 1993;260:816-19.

6 Honchel R, Halling KC, Schaid DJ, et al. Microsatellite instability in Muir-Torre syndrome. Cancer Res 1994;54: instability

7 Hamilton SR, Liu B, Parsons RE, et al. The molecular basis of Turcot's syndrome. N Engl $\mathcal{F}$ Med 1995;332:839-47.

8 Wooster R, Cleton-Jansen AM, Collins N, et al. Instability of short tandem repeats (microsatellites) in human cancer. Nat Genet 1994;6:152-6.

9 Arzimanoglou II, Gilbert F, Barber HRK. Microsatellite instability in human solid tumors. Cancer 1998;82:180820.

10 Lothe RA, Peltomaki P, Meling GI, et al. Genomic instability in colorectal cancer: relationship to clinicopathological variables and family history. Cancer Res 1993;53:5849-52.

11 Seruca R, Santos NR, David L, et al. Sporadic gastric cancers with microsatellite instability display a particular clinicopathologic profile. Int f Cancer 1995;64:32-6.

12 Dos Santos NR, Seruca R, Constancia M, et al. Microsatellite instability at multiple loci in gastric carcinoma: clinicopathological implications and prognosis. Gastroenterology pathological imp

13 Paulson TG, Wright FA, Parker BA, et al. Microsatellite instability correlates with reduced survival and poor disease prognosis in breast cancer. Cancer Res 1996;56:4021-6.

14 Aebi S, Kurdi-Haidar B, Gordon R, et al. Loss of DNA mismatch repair in acquired resistance to cisplatin. Cancer Res 1996;56:3087-90.

15 Parsons R, Li G-M, Longley MJ, et al. Hypermutability and mismatch repair deficiency in RER+ tumor cells. Cell 1993;75:1227-36.
16 Fishel R, Lescoe MK, Rao MRS, et al. The human mutator gene homolog MSH2 and its association with hereditary nonpolyposis colon cancer. Cell 1993;75:1027-38.

17 Bronner CE, Baker SM, Morrison PT, et al. Mutation in the DNA mismatch repair gene homologue hMLH1 is associated with hereditary non-polyposis colon cancer. Nature 1994;368:258-61.

18 Katabuchi H, van Rees B, Lambers AR, et al. Mutations in DNA mismatch repair genes are not responsible for microsatellite instability in most sporadic endometrial carcinomas. Cancer Res 1995;55:5556-60.

19 Dams E, Van de Kelft EJ, Martin JJ, et al. Instability of microsatellites in human gliomas. Cancer Res 1995;55:1547-9.

20 Izumoto S, Arita N, Ohnishi T, et al. Microsatellite instability and mutated type II transforming growth factor- $\beta$ receptor gene in gliomas. Cancer Lett 1997;112:251-6.

21 Mizoguchi $M$, Inamura $T$, Ikezaki $K$, et al. Patient survival and microsatellite instability in gliomas by high-resolution fluorescent analysis. Oncology Reports 1999;6:791-5.

22 Pykett MJ, Murphy M, Harnish PR, et al. Identification of a microsatellite instability phenotype in meningiomas. Cancer Res 1994;54:6340-3.

23 Zhu J, Guo S-Z, Beggs AH, et al. Microsatellite instability analysis of primary human brain tumors. Oncogene 1996;12:1417-23.

24 Zhu JJ, Santarius T, Wu X, et al. Screening for loss of heterozygosity and microsatellite instability in oligodendrogliomas. Genes Chromosomes Cancer 1998;21:207-16.

25 Lundin DA, Blank A, Berger MS, et al. Microsatellite instability is infrequent in sporadic adult gliomas. Oncology Res 1998;10:421-8

26 Simon M, Kokkino AJ, Warnick RE, et al. Role of genomic instability in meningioma progression. Genes Chromosomes Cancer 1996;16:265-9.

27 Ottini L, Esposito DL, Richetta A, et al. Alterations of microsatellites in neurofibromas of von Recklinghausen's disease. Cancer Res 1995;55:5677-80.

28 Levitt RC, Kiser MB, Dragwa C, et al. Fluorescence-based resource for semiautomated genomic analyses using microsatellite markers. Genomics 1994;24:361-5.

29 Cawkwell L, Li D, Lewis FA, et al. Microsatellite instability in colorectal cancer: improved assessment using fluorescent polymerase chain reaction. Gastroenterology 1995;109: 465-71

30 Oda S, Oki E, Maehara Y, et al. Precise assessment of microsatellite instability using high resolution fluorescent microsatellite analysis. Nucleic Acids Res 1997;25:3415-20.

31 Kleihues P, Burger PC, Scheithauer BW. Histological typing of tumors of the central nervous system. 2nd ed. Berlin: World Health Organization: Springer-Verlag, 1993:2-20.

32 Daumas-Duport C, Scheithauer BW, O'Fallon J, et al. Grading of astrocytomas. A simple and reproducible method. Cancer 1988;62:2152-65.

33 Burton MP, Schneider BG, Brown R, et al. Comparison of histologic stains for use in PCR analysis of microdissected, paraffin-embedded tissues. Biotechniques 1998;24:86-92.

34 Wright DK, Manos MM. Sample preparation from paraffin-embedded tissues. In: Innis MA, Gelfand DH, paraffin-embedded tissues. In: Innis MA, Gelfand $\mathrm{DH}$,
Sninsky JJ, et al, eds. PCR protocols: a guide to methods and applications. San Diego: Academic Press, 1990:153-8.

35 Gall K, Pavelic J, Jadro-Santel D, et al. DNA amplification by polymerase chain reaction from brain tissues embedded in paraffin. Int f Exp Pathol 1993;74:333-7.

36 Mills KA, Even D, Murray JC. Tetranucleotide repeat polymorphism at the human $\alpha$ fibrinogen locus (FGA). Hum Mol Genet 1992;1:779.

37 Sharma V, Litt M. Tetranucleotide repeat polymorphism at the D21S11 locus. Hum Mol Genet 1992;1:67.

38 Lareu MV, Pestoni C, Schurenkamp M, et al. A highly variable STR at the D12S391 locus. Int F Legal Med 1996;109: $134-8$.

39 http://www.gdb.org

40 Lareu MV, Barral S, Salas A, et al. Sequence variation of a hypervariable short tandem repeat at the D1S1656 locus. Int f Legal Med 1998;111:244-7.

41 Dietmaier W, Wallinger S, Bocker T, et al. Diagnostic microsatellite instability: definition and correlation with mismatch repair protein expression. Cancer Res 1997;57:474956.

42 Shaw EG, Scheithauer BW, O'Fallon JR. Supratentorial gliomas: a comparative study by grade and histologic type. f Neurooncol 1997;31:273-8.

43 Loeb LA. Mutator phenotype may be required for multistage carcinogenesis. Cancer Res 1991;51:3075-9.

44 Rogers BB, Alpert LC, Hine EAS, et al. Analysis of DNA in fresh and fixed tissue by the polymerase chain reaction. $\mathrm{Am}$ f Pathol 1990;136:541-8.

45 Kirsch M, Zhu JJ, Black PM. Analysis of the BRCA1 and BRCA2 genes in sporadic meningiomas. Genes Chromosomes Cancer 1997;20:53-9.

46 Gonzalez-Zulueta M, Ruppert JM, Tokino K, et al. Microsatellite instability in bladder cancer. Cancer Res 1993;53: $5620-3$. 